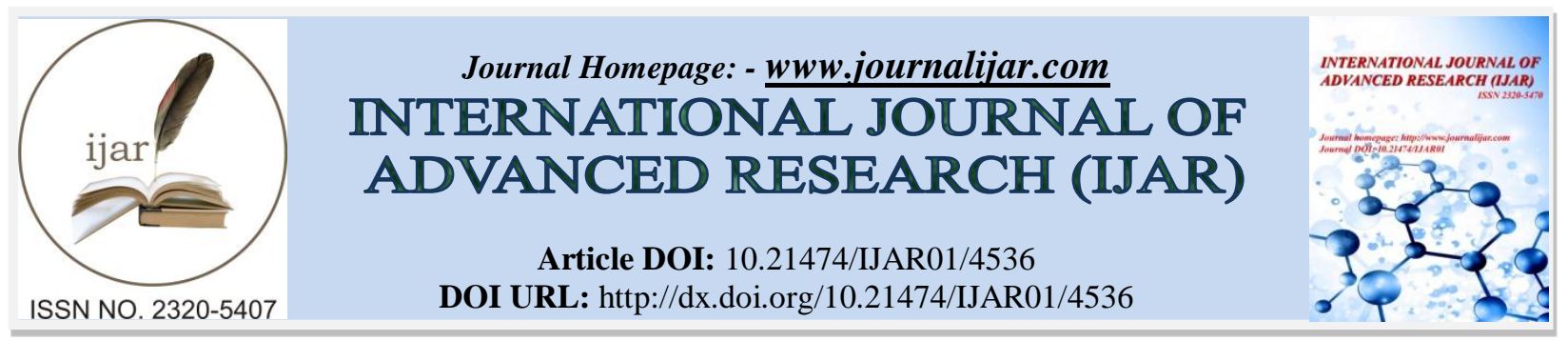

RESEARCH ARTICLE

\title{
IN-VITRO MARGINAL FIT OF ALL-CERAMIC ENDOCROWNS WITH DIFFERENT PREPARATION DEPTHS: A SYSTEMATIC REVIEW.
}

Eman Ezzat Youssef Hassanien ${ }^{1}$, Gihan Abdel Hady El-Naggar ${ }^{2}$ and Omnia Abdel Hameed El-Sheehy ${ }^{2}$

1. Assistant Lecturer, Department of Fixed Prosthodontics, Faculty of Oral and Dental Medicine, Cairo

University, Egypt.

2. Professor, Department of Fixed Prosthodontics, Faculty of Oral and Dental Medicine, Cairo University, Egypt.

\section{Manuscript Info}

.............

Manuscript History

Received: 19 April 2017

Final Accepted: 21 May 2017

Published: June 2017

Key words:-

Endocrown, margin, fit

\section{Abstract}

The present systematic review was performed to evaluate the in vitro marginal fit studies of endocrown restorations with varying preparation depths. A systematic literature search was performed in three databases: PubMed, LILACS and Web of Science up to June 2017. Only in-vitro studies evaluating the marginal accuracy were included. Clinical studies, case series, case reports, pilot studies, reviews, non-dental studies and studies that evaluated properties other than marginal fit were excluded. From the 481 eligible articles, two studies were employed in the present review. The included studies showed that increasing the preparation depth increases the marginal discrepancy. Although further studies are required to confirm and justify the present findings, increasing the preparation depth should be approached with extreme caution to avoid violating marginal adaptation.

Copy Right, IJAR, 2017,. All rights reserved.

\section{Introduction:-}

The use of "endocrowns" in restoring endodontically treated teeth has become a major interest nowadays. Being adhesively bonded, depending of the available surface area for bonding, some researchers speculated that increasing the depth of the preparation would increase the available surface area and hence enhance the bond strength and the survival of the restoration. However, the effect of such extension might affect the marginal fit of the restorations in such cases. Thus, the present systematic review was conducted aiming at finding conclusive information about the effect of the preparation depth on the marginal fit of all-ceramic endocrowns.

\section{Materials and Methods:-}

This systematic review was guided by the guidelines of the PRISMA Statement (Preferred Reporting Items for Systematic Reviews and Meta-Analyses) [1]. The research question was: Does endocrown preparation depth affect the marginal fit of the final restoration?

\section{Search strategy:-}

Three online databases (PubMed, Lilacs, and Web of Science) were searched until June 2017. The articles identified by the databases were imported to Endnote X8 software (Thompson Reuters, USA) to remove all duplicates ( $\mathrm{n}=77$ ). The search terms used were ("endocrown*" Or "endo-crown*" Or "endo crown*" Or "endodontic crown*" Or 
"endodontic-crown*” Or "no-post" Or "depulp*" Or de-pulp*”) combined with ("margin*” Or "fit*"). All searches were conducted with the "English" filter turned on.

\section{Study Selection:-}

Titles and abstracts of all articles were assessed by two authors independently. The included articles were in-vitro studies evaluating the marginal fit of endocrown restorations. Clinical studies, case series, case reports, pilot studies, reviews, non-dental studies and studies that evaluated properties other than marginal fit were excluded. Full-texts of the potentially relevant articles (apparently relevant to the inclusion criteria) or those with insufficient title and abstract data were gathered and meticulously assessed to identify studies specifically evaluating the effect of preparation depth on marginal accuracy. Two reviewers reviewed the full-texts of the articles independently. Any disagreement concerning the eligibility of the included studies was resolved by discussion or by a third reviewer. Only studies that satisfied all the eligibility criteria were included.

\section{Data Extraction:-}

The data of interest of the studies that satisfied all the eligibility criteria were extracted and tabulated.

\section{Results:-}

\section{Search strategy:-}

The procedure of articles selection was summarized in Fig.1 guided by PRISMA Statement. After systematic search, a total number of 481 studies were identified. After title and abstract screening, 473 did not meet the eligibility criteria and were excluded. Of the 8 studies remained for detailed reviewing, 6 studies could not be included: 1 case study [2]; 1 study analyzed only fracture resistance and micro-leakage [3]; and 4 studies evaluated marginal adaptation but did not evaluate the effect of preparation depth [4-7]. Only two studies [8-9] were included in the present systematic review.

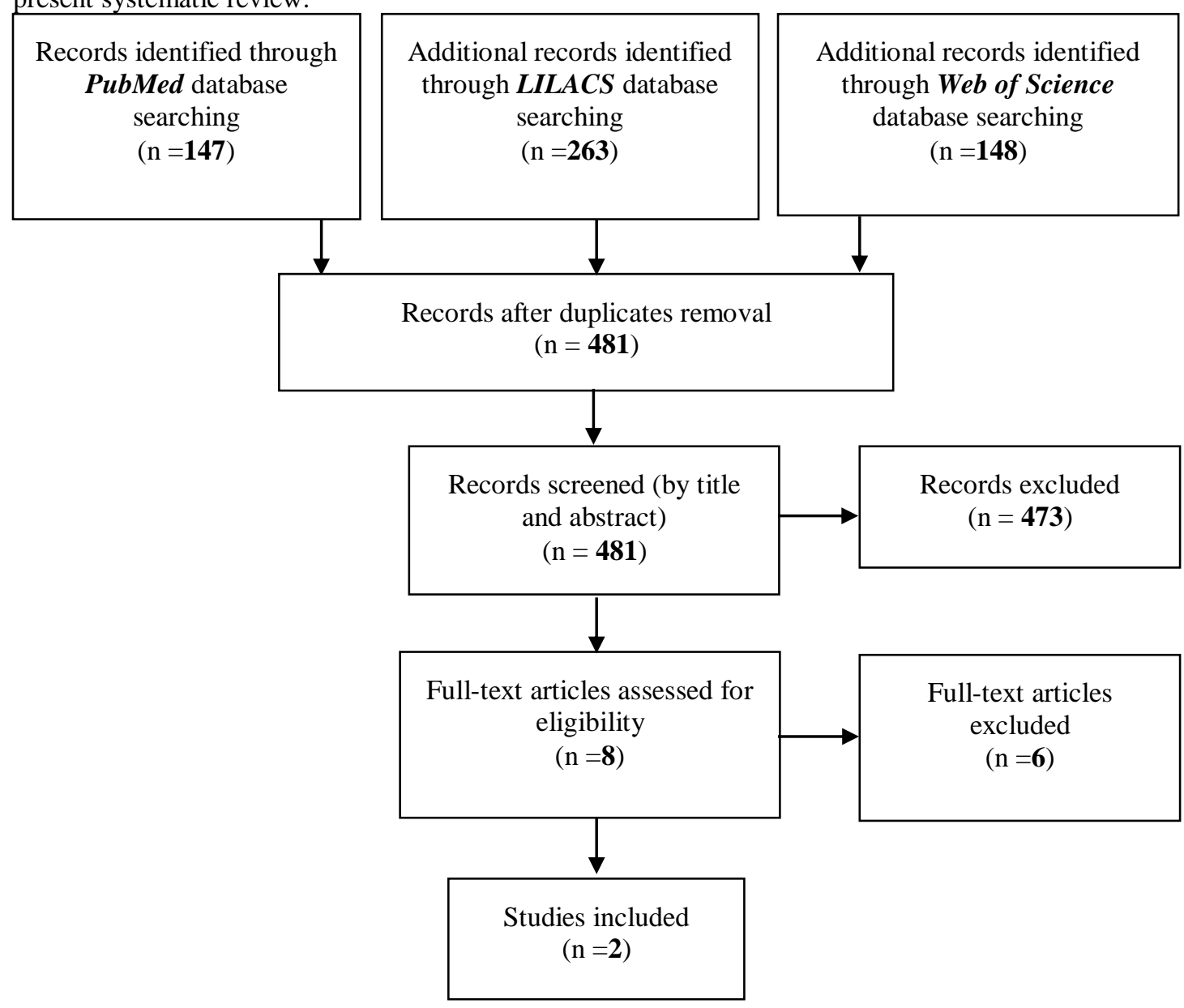

Fig. 1:- Flow chart of articles selection process. 


\section{Descriptive Analysis:-}

The two in-vitro studies accepted for the present systematic review were in the years 2016 and 2017 (Table 1). Both studies involved a sample size of 12 posterior mandibular teeth. One article was conducted on acrylic resin teeth while the other was conducted on human teeth. Such heterogeneity made the conduction of a meta-analysis not affordable. The first article evaluated hybrid ceramic endocrowns in mandibular 1st molar, while the other evaluated lithium disilicate ceramic endocrowns in mandibular 1st and 2nd molar. Table 2-3 defines the groups evaluated and the mean discrepancy measurements ( \pm standard deviation).

Table 1:- Demographic data of the included study

\begin{tabular}{|c|c|c|c|c|c|c|c|c|}
\hline Ref & Author & year & $\begin{array}{c}\text { Teeth } \\
\text { origin }\end{array}$ & $\begin{array}{c}\text { Teeth } \\
\text { type }\end{array}$ & $\begin{array}{c}\text { No. of } \\
\text { Groups }\end{array}$ & $\begin{array}{c}\text { No of } \\
\text { subgroups/ } \\
\text { group }\end{array}$ & $\begin{array}{c}\text { No. of } \\
\text { sample/ } \\
\text { group }\end{array}$ & Outcomes \\
\hline$[8]$ & $\begin{array}{c}\text { Gaintantzopoulou } \\
\text { \& El- } \\
\text { Damanhoury }\end{array}$ & 2016 & $\begin{array}{c}\text { Acrylic } \\
\text { resin } \\
\text { (Nissen) }\end{array}$ & Md:6 & $\begin{array}{c}3 \\
\text { (acc. } \\
\text { preparation) }\end{array}$ & - & 12 & $\begin{array}{c}\text { Marginal and } \\
\text { internal } \\
\text { adaptation }\end{array}$ \\
\hline$[9]$ & Shin et al. & 2017 & Human & $\begin{array}{c}\text { Md: } \\
6 \& 7\end{array}$ & $\begin{array}{c}2 \\
\text { (acc. } \\
\text { CAD/CAM } \\
\text { systems) }\end{array}$ & $\begin{array}{c}2 \\
\text { (acc. } \\
\text { preparation) }\end{array}$ & 24 & $\begin{array}{c}\text { Marginal and } \\
\text { internal } \\
\text { discrepancies }\end{array}$ \\
\hline
\end{tabular}

Md: mandibular, acc.: according to

Table 2:- The groups evaluated

\begin{tabular}{|l|c|c|c|c|c|c|c|c|c|c|c|}
\hline \multirow{2}{*}{ Ref } & \multicolumn{9}{|c|}{ Laboratory procedures } & \multicolumn{2}{c|}{ Testing parameters } \\
\cline { 2 - 10 } & Teeth & $\begin{array}{c}\text { Conv. } \\
\text { angle }\end{array}$ & $\begin{array}{c}\text { 2mm } \\
\text { Prep. } \\
\text { Depth }\end{array}$ & $\begin{array}{c}\text { 3mm } \\
\text { Prep. } \\
\text { Depth }\end{array}$ & $\begin{array}{c}\text { 4mm } \\
\text { Prep. } \\
\text { Depth }\end{array}$ & $\begin{array}{c}\text { Type of } \\
\text { impress } \\
\text { ion }\end{array}$ & $\begin{array}{c}\text { Restoration } \\
\text { material }\end{array}$ & $\begin{array}{c}\text { Fabrication } \\
\text { system }\end{array}$ & $\begin{array}{c}\text { Test } \\
\text { technique }\end{array}$ & $\begin{array}{c}\text { Before } \\
\text { cem. }\end{array}$ & $\begin{array}{c}\text { After } \\
\text { cem. }\end{array}$ \\
\hline$[8]$ & Manual & $8^{\circ}-10^{\circ}$ & $\sqrt{ }$ & $\sqrt{ }$ & $\sqrt{ }$ & Optical & $\begin{array}{c}\text { Hybrid } \\
\text { ceramic } \\
\text { (Vita } \\
\text { Enamic) }\end{array}$ & $\begin{array}{c}\text { Cerec AC } \\
\text { (v.4) }\end{array}$ & $\begin{array}{c}\text { Micro- } \\
\text { tomography }\end{array}$ & $\sqrt{ }$ & - \\
\hline$[9]$ & Manual & $10^{\circ}$ & $\sqrt{ }$ & - & $\sqrt{ }$ & Optical & $\begin{array}{c}\text { Lithium } \\
\text { disilicate } \\
\text { (IPS e.max } \\
\text { CAD) }\end{array}$ & $\begin{array}{c}\text { Cerec AC } \\
\text { (v 4.2) } \\
\text { E4D } \\
\text { (v 2.0) }\end{array}$ & $\begin{array}{c}\text { Micro- } \\
\text { tomography }\end{array}$ & $\sqrt{ }$ & $\sqrt{ }$ \\
\hline
\end{tabular}

Prep.: preparation, Conv.: convergence, Cem.: cementation

Table 3:- The resultant average mean values ( \pm standard deviation)

\begin{tabular}{|c|c|c|c|c|c|c|}
\hline \multirow{3}{*}{ Ref } & \multicolumn{6}{|c|}{ Average mean values $\mu \mathrm{m}( \pm \mathrm{SD})$} \\
\hline & \multicolumn{2}{|c|}{ 2mm Prep. Depth } & \multicolumn{2}{|c|}{ 3mm Prep. Depth } & \multicolumn{2}{|c|}{ 4mm Prep. Depth } \\
\hline & Before cem. & After cem. & Before cem. & After cem. & Before cem. & After cem. \\
\hline [8] & $\begin{array}{l}M^{\#}: 40.6(4.1) \\
M^{*}: 65.9(12.1)\end{array}$ & - & $\begin{array}{c}M^{\#}: 48.9(13.8) \\
M^{*}: 76.2(12.0)\end{array}$ & 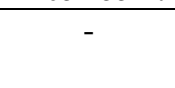 & $\begin{array}{l}M^{\#}: 59.4(9.6) \\
M D^{*}: 77.6(5.9)\end{array}$ & 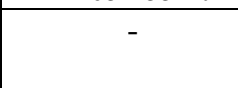 \\
\hline [9] & $\begin{array}{l}\quad \mathrm{AD}^{\wedge}: \\
\text { - Cerec AC: } \\
\text { 163.96(98) } \\
\text { - E4D: } \\
\text { 204.12(105.04) }\end{array}$ & $\begin{array}{l}\quad \mathrm{AD}^{\wedge}: \\
\text { - } \text { Cerec AC: } \\
\text { 207.61(108.04) } \\
\text { - } \mathrm{E} 4 \mathrm{D} \\
197.34(104.48)\end{array}$ & - & - & \begin{tabular}{|l}
$\quad \mathrm{AD}^{\wedge}:$ \\
- Cerec AC: \\
182.34(99.76) \\
• $\mathrm{E} 4 \mathrm{D}:$ \\
$211.25(128.56)$
\end{tabular} & $\begin{array}{l}\quad \mathrm{AD}^{\wedge}: \\
\text { - Cerec AC: } \\
\text { 190.71 (113.96) } \\
\text { - E4D: } \\
\text { 196.18(108.69) }\end{array}$ \\
\hline & $\begin{array}{l}\text { MD } \\
\text { - Cerec AC: } \\
\text { 98.93(66.1) } \\
\text { - E4D: } \\
\text { 120.15(64.29) }\end{array}$ & $\begin{array}{l}\text { MD } \$ \\
\text { - Cerec AC: } \\
\text { 144.02(76.06) } \\
\text { - E4D: } \\
\text { 128.64(81.25) }\end{array}$ & & & $\begin{array}{l}\quad \mathrm{MD}^{\$}: \\
\text { - Cerec AC: } \\
\text { 107.82(82.18) } \\
\text { - E4D: } \\
\text { 90.18(58.26) }\end{array}$ & $\begin{array}{l}\text { MD } \$ \\
\text { - Cerec AC: } \\
\text { 138.06(95.33) } \\
\text { - E4D: } \\
\text { 127.45(77.37) }\end{array}$ \\
\hline
\end{tabular}

Prep.: preparation, Conv.: convergence, Cem.: cementation 
$\mathrm{MG}^{\#}$ : Marginal gap, $\mathrm{MD}^{*}$ : Marginal discrepancy, $\mathrm{AD}^{\wedge}$ : Average discrepancy, $\mathrm{MD}^{\$}$ : Marginal discrepancy obtained from cavo-surface angle measurement

\section{Discussion:-}

According to the present systematic review, the marginal fit of the endocrown restorations with short intra-coronal extension seemed to be better than longer ones.

The success and serviceability of endocrowns are now of great concern. Being adhesively bonded, many researchers aimed at increasing the surface area for bonding by manipulating the preparation parameters. In cases with very little remaining coronal tooth structure, some clinicians tend to increase the intra-pulpal extension, an approach that could definitely affect the restoration retention and adaptation. They base their approach on the concept that lateral forces exerted on the endocrown restoration are transmitted to the pulp chamber walls through the adhesive bond.[10] Thus, the deeper the retentive cavity, the more the endo-anchor, and hence the greater the surface area available for adhesive retention and force dissipation.[10]

Marginal fit of indirect restorations is a very important parameter that affects both the periodontal condition and the restorations longevity.[8] Increasing the marginal discrepancy increases the cement surface exposed to the oral environment, causing cement degradation and esthetic deterioration,[8] in addition to acting as a site for crack initiation and propagation causing loss of restoration retention, debonding, and subsequent failure.

Marginal fit of all-ceramic endocrowns can be affected by many factors, the preparation parameters (depth, convergence angle, preparation smoothness), impression technique, scanning procedure (in case of optical impression), software design, milling, and restoration material.

In the two in-vitro included studies, the convergence angle was almost the same; being $10^{\circ}$ in one study and a range between $8-10^{\circ}$ in the other, hence such factor can be eliminated when comparing the results of both studies. Optical impression technique (CEREC Bluecam), designing and milling was employed in both studies following the same procedures in the Cerec AC groups, however in one study E4D was additionally used in a separate group. Thus, the previous factors can also be eliminated.

The differences between the studies lied in the type of the teeth origin being acrylic resin in one study and human in the other, and the restoration materials used being hybrid ceramic (Vita ENAMIC) in one study and lithium disilicate (e.max CAD) in the other. The teeth type might have an influence on the smoothness of the preparation. However, using e.max CAD with post-milling crystallization process might also influence the final outcome. These differences might attribute to the difference in the discrepancy values between the two studies.

Both studies tested a preparation depth of $2 \mathrm{~mm}$ and $4 \mathrm{~mm}$, with one study testing additional group with $3 \mathrm{~mm}$ depth. In both studies, the marginal discrepancy increased with the increase of the preparation depth. This might be attributed to some limitations of the scanning process regarding deeper cavities. Although the CEREC Bluecam has a field depth up to $15 \mathrm{~mm}$, enabling it to capture deep preparations, one author speculated that the optical contrasting powder application, camera misalignment, or distance between the scanned surface and the camera might be the cause of such problem. [8] However, this was also the case in E4D system. Thus, this justification might not be the actual reason. Another reason might be the accuracy of the designing software and milling machines.

The author of the present review speculate that using more advanced optical cameras, designing software, and milling machines might change the obtained results tremendously.

\section{Conclusion and clinical significance:-}

The available literature found suggested that increasing the preparation depth increases the marginal discrepancy. Although further studies are required to confirm and justify the present findings, increasing the preparation depth should be approached with extreme caution to avoid violating marginal adaptation. 


\section{References:-}

1. Moher D, Liberati A, Tetzlaff J, Altman DG, The PRISMA Group. Preferred reporting items for systematic reviews and meta-analyses: The PRISMA statement, J. Clin. Epidemiol. 2009; 62:1006-1012.

2. Fages $M$ and Bennasar B. The endocrown: A different type of all-ceramic reconstruction for molars. J Can Dent Assoc. 2013;79:d140.

3. El-Damanhoury HM, Haj-Ali RN and Platt JA. Fracture resistance and microleakage of endocrowns utilizing three CAD-CAM blocks. Oper Dent. 2015;40:201-10.

4. Forberger N and Göhring TN. Influence of the type of post and core on in vitro marginal continuity, fracture resistance, and fracture mode of lithia disilicate-based all-ceramic crowns. J Prosthet Dent. 2008;100:264-73.

5. Ramirez-Sebastia A, Bortolotto T, Roig M and Krejci I. Composite vs ceramic computer-aided design/computer-assisted manufacturing crowns in endodontically treated teeth: Analysis of marginal adaptation. Oper Dent. 2013;38:663-73.

6. Rocca GT, Saratti CM, Poncet A, Feilzer AJ and Krejci I. The influence of FRCs reinforcement on marginal adaptation of $\mathrm{CAD} / \mathrm{CAM}$ composite resin endocrowns after simulated fatigue loading. Odontology. 2016;104:220-32.

7. Stricker EJ and Gohring TN. Influence of different posts and cores on marginal adaptation, fracture resistance, and fracture mode of composite resin crowns on human mandibular premolars. An in vitro study. J. Dent. 2006;34:326-35.

8. Gaintantzopoulou MD and El-Damanhoury HM. Effect of preparation depth on the marginal and internal adaptation of computer-aided design/computer-assisted manufacture endocrowns. Oper Dent. 2016;41:607-16.

9. Shin Y, Park S, Park JW, Kim KM, Park YB and Roh BD, et al. Evaluation of the marginal and internal discrepancies of CAD-CAM endocrowns with different cavity depths: An in vitro study. J. Prosthet. Dent.; 2017;117:109-15.

10. Bindl A and Mörmann WH. Clinical evaluation of adhesively placed Cerec endo-crowns after 2 YearsPreliminary results. J Adhes. Dent. 1999;1:255-65. 